\title{
OUR BRAIN "KanT" Tell Us? - \\ A Kantian Perspective of How Neuroscience \\ Challenges OUR Notions \\ OF MORAL RESPONSIBILITY AND THE LEGAL IMPLICATIONS
}

\author{
Joel Quek*
}

\begin{abstract}
Neuroscientific research has not only proved to be vital in our increasing understanding of human nature, but has also led to much normative discourse revolving around morality and law. There has been much work done regarding how neuroscience should inform us on issues regarding moral responsibility. In this paper, I propose to employ a Kantian moral framework to consider these issues more carefully. I argue that generally, neuroscience cannot undermine the concept that rational beings are morally responsible for their actions. However, within the same Kantian moral philosophical framework, I will consider how it is that certain individuals can be excused for their actions or have their responsibility mitigated. This will be done by focusing on the interaction between neuroscientific evidence and the capacity of certain individuals to engage with categorical and hypothetical imperatives. I will consider how it is that neuroscientific evidence can serve as an $a$ priori excusing condition for moral responsibility, and equally importantly, when it cannot. I then go on to explore how our understanding of the workings of the brain can improve legal doctrine. I suggest that neuroscience can help to demonstrate that certain psychological criteria underlying particular legal doctrine might be inaccurate, and to improve our sentencing policies in order to better fulfil both retributive and rehabilitative aims and the criminal law.
\end{abstract}

\section{A. INTRODUCTION}

The rapid development of neuroscientific research has led to the suggestion that our growing knowledge of how the brain works will revolutionise our idea of moral and legal responsibility. ${ }^{1}$ This essay seeks to achieve two aims. The first aim, which is the main focus of the essay, would be to employ Kantian moral philosophy in addressing how

\footnotetext{
" I would like to extend special thanks to Professor Michael Freeman and Professor Stephen Guest for their mentorship, guidance and inspiration in writing this paper. Thanks also go to Associate Professor Yap Po Jen for his helpful comments. The usual caveat applies.

${ }^{1}$ S. Morse, 'Lost in Translation?: An Essay on Law and Neuroscience' in M. Freeman (ed), Law and Neuroscience (Oxford University Press 2011) 529.
} 
neuroscience should inform us on issues regarding moral responsibility. The second would be to explore how the law, in so far as it is informed by morality, should take into account neuroscientific research. On a preliminary note, I point out that moral responsibility is different from legal responsibility. There are many reasons why we may rightly sequester or even incarcerate people whom we believe to be dangerous to others in society even though we do not think that they are morally culpable for their actions. ${ }^{2}$ Also, I adopt a Kantian moral framework, because I believe that our ability to reason is what allows us to even comprehend the idea of responsibility in the first place. Kantian moral philosophy which is premised on the capacity of rational beings for pure practical reason will prove to be a fruitful foundation on which to base critical analysis of moral responsibility. For want of space, this essay will not address the long standing debate involving the three main Western classical moral theories of utilitarianism, deontology and virtue theory, and their relation to neural mechanisms of moral cognition. ${ }^{3}$

The first part of the essay outlines areas of Kantian moral philosophy in order to allow us to understand what it means to be morally responsible for one's actions. The second part of this essay addresses neuroscientific challenges to the concept of responsibility itself. In the third part of the essay, I explore how discoveries in neuroscience can help us to decide when we should excuse or mitigate moral responsibility in certain individuals. Lastly, I go on to discuss the ways in which neuroscience can help to change and improve legal doctrines and practices.

\section{B. Kantian Moral Philosophy}

I set out the moral philosophy of Kant by first establishing what Kant means by having a good will. I then go on to discuss Kant's conception of freedom, before stating what Kant means to act morally. Lastly, I establish the concept of moral responsibility which will be used in this essay.

\footnotetext{
${ }^{2}$ N. Levy, Neuroethics: Challenges for the $21^{\text {st }}$ Century (Cambridge University Press 2007) 257.

${ }^{3}$ W. D. Casebeer, 'Moral Cognition and Its Neural Constituents' in W. Glannon, Defining Right and Wrong in Brain Science: Essential Readings in Neuroethics (Dana Press 2007) 207.
} 


\section{Kantian Concept of the Good Will}

In Kant's view, common reason allows us to recognise many different forms of good, such as wealth, power, talent and intellect, and even goodness of kindly or generous dispositions. However, he also opines that the only good which is unconditional is that of the good will. A good will is also distinguished from a will that acts to achieve an ulterior end. The will, if it is to be a good will, must act from duty. ${ }^{4}$ Some critics of Kant have picked up on the fact that since good is not defined substantially, there is no meaning to the good will. Kant's reply to this was that good in this sense, was acting out of duty in reverence for the moral law which obligates all free and rational beings. ${ }^{5}$

\section{Kantian Conception of Freedom}

Kant expresses the idea that as rational beings, our will is an ought, which expresses a necessity for action as a law. We are interested in acting in a particular way because we are motivated by our various desires for what we hope to achieve. ${ }^{6}$ The ability to act from interest, free of internal and external impediments such that we can do anything we choose to is what Kant calls 'psychological freedom'. 7 However, to base our understanding of freedom on experience, describes only prudential, and not morally worthy conduct. Kant then argues that freedom in the full moral sense is to not allow ourselves to act from interest, but rather to take an immediate interest in acting. We must be able to exercise our will without being influenced to do so by any causes except our own reason, which include our desires and inclinations. ${ }^{8}$ This conception of freedom is a transcendental idea of reason, because it originates only in our own reason without recourse to any possible sensory experience. This is what Kant calls to possess the power of "pure practical reason'. 9 This conception of freedom can be defined both negatively and positively.

\footnotetext{
4 I. Kant, Groundwork of the Metaphysic of Morals (1785), tr. M. J. Gregor (Cambridge University Press 1997) 7/393.

${ }^{5}$ I. Kant, Critique of Practical Reason (1788), tr. L. W. Beck (Chicago, 1949) 74, 78, 117, 158; see also R. J. Sullivan, Immanuel Kant's Moral Theory (Cambridge University Press 1989) 133-134.

${ }^{6}$ Kant, Groundwork of the Metaphysic of Morals (n 4), 35/427.

${ }^{7}$ Sullivan, Immanuel Kant's Moral Theory (n 5), 45.

${ }^{8}$ Kant, Critique of Practical Reason (n 5), 15-16.

${ }^{9}$ ibid 22.
} 
The negative conception of freedom is our ability to 'restrain and overcome inclinations by reasons' when we act. ${ }^{10}$ The positive conception of freedom is the power of absolute causal self-determination, enabling us to act autonomously based on nothing but our own reasoning. ${ }^{11}$ Importantly, this Kantian conception of freedom means that 'a free will and a will under moral laws are one and the same'. ${ }^{12}$ Therefore, to be free means to be a morally responsible person. ${ }^{13}$

\section{Kantian Morality}

Kant in analysing human agency begins with the proposition that all practical rules always appear to us as commands or imperatives, because as human beings we are only contingently rational. ${ }^{14}$ Such imperatives appear to us in two forms, categorical and hypothetical. Hypothetical imperatives are based on our desires and inclinations, and command us to act with ends in mind derived from interest. This imperative is hypothetical, because it can cease to exist just by altering our inclinations and desires. The categorical imperative speaks to us as a moral rule which prevents us from acting immorally. This imperative is unconditional, because morality is grounded in our own reason, and as rational beings, we cannot choose to discard it like how we can do with our desires. ${ }^{15}$ Therefore, in order of us to act morally, we must presume the Categorical Imperative as our ultimate norm. ${ }^{16}$ This is made possible, as Kant explains, because as rational beings in the world of nature, we see the world from 'two standpoints'. ${ }^{17}$ When we imagine ourselves trying to understand how we affect and are affected in the world of sense (the 'phenomenal world'), we have to regard ourselves as subject to the laws of causal determination. Because we reason practically about how we should act, we belong to the intelligible world (the 'noumenal world'),

\footnotetext{
${ }^{10}$ I. Kant, Metaphysics of Morals (1797), tr. M. J. Gregor (Cambridge University Press 1996) 481.

${ }^{11}$ ibid, 213-14.

${ }^{12}$ Kant, Groundwork of the Metaphysic of Morals (n 4), 52/447.

${ }^{13}$ Sullivan, Immanuel Kant's Moral Theory (n 5), 46.

${ }^{14}$ Kant, Groundwork of the Metaphysic of Morals (n 4), 24-26/413-14.

15 ibid, 30/420.

${ }^{16}$ Sullivan, Immanuel Kant's Moral Theory (n 5), 50.

${ }^{17}$ Kant, Groundwork of the Metaphysic of Morals (n 4), 55/450.
} 
where we are free from all causal determination and are bound only by the moral law as autonomous beings. ${ }^{18}$

In this essay, I will not explore exactly how Kant tells us the Categorical Imperative commands us to act. I will simply state that the Categorical Imperative is a purely formal criterion, which requires no special methodology except for the capacity for pure practical reason. ${ }^{19}$ Therefore, all rational beings can know how the Categorical Imperative commands, and of the obligations the moral law generates. ${ }^{20}$ The problem this gives rise to is that we must be held culpable for erroneous moral judgments about our obligations, and that there is an assumption that these erroneous judgments must have been adopted in bad faith and be due to bad moral character. ${ }^{21}$ This is a very pertinent question, since as social creatures we all understand that there are varying capacities for rationality, and hence, quality of objective judgment. Kant does recognise that it is indeed possible that one might at times err 'in objective judgment as to whether something is a duty or not' and that the principles a person of good character adopts 'might occasionally be mistaken and imperfect'. ${ }^{22}$ However, I believe that this allows us to understand that moral enlightenment is a journey which all rational beings are gifted with the capacity to begin on. In fact, such a contention is in light with our intuitions on moral responsibility, given that we deem infants to be less morally responsible than adults, and we adjust this scale of culpability as one grows in capacity to reason.

\section{The Concept of Moral Responsibility}

Kantian moral philosophy tells us that as long as we have the relevant mental capacities to act freely, we should be held responsible for our actions. As contingently rational beings, we do not necessarily have to exercise our free will and practical reason in every instance to be morally responsible. As long as we understand that morality commands us as a law, and that action should be governed by reason, we must be morally

\footnotetext{
${ }^{18}$ Kant, Groundwork of the Metaphysics of Morals (n 4), 57/453.

${ }^{19}$ Kant, Metaphysics of Morals (n 10), 411.

20 I. Kant, Lectures on Ethics (1780-85), tr. L. Infield (London: Methuen, 1930) $355 / 133$.

21 ibid. , 355/132-33.

${ }^{22}$ Kant, Metaphysics of Morals (n 10), 401.
} 
responsible when we fail to do so. Yet free will and reason is not an allor-nothing capacity. It is a capacity that comes in degrees along a spectrum of control since we are beings in the world of sense. There are two possible reasons that can exempt a being from the moral law. The first reason is that to argue that the being is not a rational being and cannot recognise the action-guiding nature of reasons. This in fact, is what we employ to absolve moral blameworthiness with animals ${ }^{23}$ and some mentally disabled adults, who are impaired in their ability to reason. Such an excuse, however, cannot be employed on ourselves, since a person cannot consistently offer a reason for doing something and yet claim to be incapable of rational thought. The second reason is to say that a being through no fault of his or her own, could not affect his or her actions through reason. Therefore, action is only determined by laws of nature and one's inclinations.

\section{Neuroscientific Challenges to the Concept of Moral RESPONSIBILITY}

Neuroscience has emerged as the latest mechanistic causal science that appears to explain behaviour in a deterministic manner which challenges the concept of free will, and therefore whether anyone can be morally responsible. The issue is whether human beings have the capacity to act uncaused by anything other than themselves, and whether this capacity should be the criteria for holding anybody morally responsible for his or her actions. However, neuroscience does not seem to add anything novel to the metaphysical problem of free will. ${ }^{24}$ If the question of the validity of free will can be answered, there will undoubtedly be profound implications for doctrines of responsibility, and social concepts such as blame and punishment. No resolution of this problem, however, seems to be in sight. ${ }^{25}$ Notwithstanding this metaphysical problem, neuroscience has challenged the concept of moral responsibility in two other ways. The first is to question whether mental states have any causal effect in the

\footnotetext{
${ }^{23}$ It is noted that there have been studies conducted by De Waal demonstrating that animals might be able to engage in robust moral reasoning. See F. R. De Waal, Good natured: The origins of right and wrong in humans and other animals (Cambridge, MA: Harvard University Press 1996).

${ }^{24}$ It simply joins the ranks of behaviourism, genetics, social structure variables etc.

${ }^{25}$ Morse (n 1) 534.
} 
first place, and the second is to question the effect moral luck should have on whether anyone should be held morally responsible. I address these challenges using Kantian moral philosophy as an analytical tool.

\section{Consciousness and Moral Responsibility}

This challenge from neuroscience comes from an experiment conducted in the 1980s by neuroscientist Benjamin Libet and his team, which suggested that because we do not consciously cause our behaviour, we are not free and therefore cannot be morally responsible. Libet measured brain activity during voluntary hand movements, and discovered that before we actually move our hand, there is a wave of brain activity indicating when our brain knows we are aware of making the decision to move, which he calls the 'readiness potential'. The timing of the readiness potential was then compared with the conscious movement of the hands of the subjects, and it was found that the moment of conscious decision making was about 300 milliseconds later than the onset of readiness potential. Assuming the veracity of the empirical data, this finding would mean that consciousness is informed of the decision but does not make it. Libet then puts forward the proposition that we ought not to hold agents responsible for actions performed 'without the possibility of conscious control'. Since consciousness comes after decisions are already made, none of our actions are consciously controlled and therefore we cannot be morally responsible for our actions.

There have been many criticisms of Libet's experiment which argue that it does not bear upon the role of consciousness in decisionmaking at all. Flanagan argues that we consciously initiate important decisions, while leaving the details of the implementation of these decisions to subpersonal processes, and this is consistent with Libet's empirical data. ${ }^{26}$ Haggard has furthered this point by arguing that although we might not consciously initiate our actions, our conscious intention is what decides how precisely we act (for example, we consciously decide whether to use our left or right hand during the

\footnotetext{
${ }^{26}$ O. Flanagan, 'Neuroscience, agency, and the meaning of life' in O. Flanagan, ed., Self-Expressions: Mind, Morals and the meaning of Life (New York: Oxford University Press 1996a) 53-64.
} 
experiment). ${ }^{27}$ Dennett has also highlighted an important point that it might be a mistake to employ the notion of a Cartesian Theatre in understanding how anything enters into our consciousness. ${ }^{28}$ Having such a notion of self, suggests that there is a precise moment at which something enters our consciousness, but as affirmed by contemporary philosophers and neuroscientists, consciousness is a 'process with fuzzy edges'. 29

Notwithstanding the earlier criticisms made, I will argue by adopting a Kantian moral philosophy, that even if we are not conscious of our decision-making process, we should still be morally responsible for our actions. Libet himself does not believe that his work shows that we lack free will or moral responsibility. He suggests that although we do not consciously initiate action, we possess the power consciously to veto actions. $^{30}$ However, in analysing this proposition according to the Kantian philosophy of the free will, I believe that this argument by Libet proves too little. As proposed by Nozick, there seems to be two ways in which we make decisions: we can weigh our reasons or we can weight our reasons. ${ }^{31}$ Weighing our reasons allow us to incorporate our beliefs, plans, values, desires and goals when working out what to do. Weighting is when we assign certain reasons a weight arbitrarily. We then make our decisions based on the fact that the weight we have attributed to doing something makes that aim important. ${ }^{32}$ According to Kant, we should weigh our reasons, as this is the process by which we engage with our capacity for rational thought and give due reverence to the moral law. Therefore, what matters in decision making is that we adopt a rational weighing of our reasons to act as opposed to arbitrary weighting. This will allow us to recognise that an active causal power to veto actions is not what matters, since this power can be exercised by either weighing or weighting of our reasons. Also, the claim that consciousness does not

${ }^{27}$ P. Haggard and B. Libet, 'Conscious intention and brain activity', (2001) 8 Journal of Consciousness Studies 47-63.

${ }^{28}$ D. Dennett, Freedom Evolves (London: Allen Lane 2003).

${ }^{29}$ Levy, Neuroethics: Challenges for the $21^{\text {st }}$ Century, 228.

${ }^{30}$ B. Libet, 'Do We Have Free Will', in B. Libet, A. Freeman, K. Sutherland, eds., The Volitional Brain: Towards a Neuroscience of Free Will (Imprint Academic 1999) 47.

${ }^{31}$ R. Nozick, Philosophical Explanations (Oxford University Press 1981).

${ }^{32}$ Levy (n 29) 235. 
learn of the agent's decisions until after they are made does not seem to matter to the question of having moral responsibility for our actions. The concept of free will is not contingent on the notion of uncaused choice, but in decisions that are made rationally, knowingly and intentionally. As long as our decisions are made rationally, and that we affect our actions accordingly, precisely when consciousness learns of this decision does not matter. ${ }^{33}$

\section{Moral Luck}

One of the challenges to the concept of moral responsibility we must address which arises out of neuroscience is the issue of moral luck. Moral luck is the assertion that people are affected by constitutive, antecedent and circumstantial conditions which then impacts on whether their actions are moral or immoral. ${ }^{34} \mathrm{~A}$ research study by a team of neuroscientists led by Caspi and Moffitt, tested the hypothesis that 'childhood maltreatment predisposes most strongly to adult violence among children whose monoamine oxidase (MAOA) is insufficient to constrain maltreatment-induced changes to the neurotransmitter system'. The central findings of the study found that males with low-MAOA activity who also suffered early childhood abuse are 9.8 times more likely to be convicted of violent crimes than males who were born into any of the other 3 permutations. These findings therefore underscore our intuitions about moral responsibility, since it leaves no room for considerations of a violent, abusive childhood and bad moral constitutive luck. ${ }^{35}$ This study is nonetheless a descriptive one, and does not lead to normative conclusions of when we should be morally responsible for our actions. However, the study demonstrates how it is that moral luck might affect our normative considerations of moral responsibility, and we have to address this challenge to our intuitions in order to determine what we ought to do. ${ }^{36}$

The question we seek to answer seems to be whether we should ascribe moral responsibility to individuals whom we know suffer from neuropsychological deficits for which they were unlucky to have in the

\footnotetext{
33 ibid. 237.

${ }^{34}$ T. Y. Blumoff, 'How (some) Criminals Are Made', in M. Freeman (n 1) 171.

35 ibid 12.

${ }^{36}$ ibid 13 .
} 
first place. ${ }^{37}$ This brings out the point, that essentially, as moral agents in the phenomenal world, there is a danger that our moral responsibilities might outrun control we have over how things turn out. ${ }^{38}$ I believe, however, that by utilising the Kantian framework in understanding the concept of moral responsibility, we will be able to adequately resolve this issue satisfactorily. By looking for the capacity for pure practical reason in deciding whether an individual should be morally responsible for his or her actions, we provide moral responsibility with 'a shelter against luck, as one realm of value that is defended against contingency,. ${ }^{39}$ Therefore, unless it can be shown that children with low-MAOA activity who also suffered early childhood abuse are incapable of minimal standards of reasoning, these children will have to be morally responsible for their actions. Nagel does not believe this to be the case, as he suggests that we have to deal with moral luck since we nevertheless assess blameworthiness based on the actor's effects, although "a substantial part of the reasons for and outcome of all that one seeks to accomplish is influenced by factors beyond one's control". ${ }^{40}$ Margaret Urban Walker also reinforces this view by pointing out that 'moral luck is part of a picture of impure agency: agency situated within the causal order in such ways as to be variably conditioned by and conditioning parts of that order, without being able to draw for all purposes a unitary boundary to its exercise at either end, nor always for particular purposes a sharp one'. ${ }^{41}$

However, I believe that the analysis made by both Nagel and Walker fail to take into account two different aspects of responsibility. As Gary Watson argues, we should distinguish between 'virtue responsibility' which is what he calls the aretaic face of responsibility, and 'capacity responsibility' which is what he calls the accountability

\footnotetext{
${ }^{37}$ ibid 7.

${ }^{38}$ M. U. Walker, 'Moral Luck and the Virtues of Impure Agency', in D. Statman (ed), Moral Luck (Albany, NY: SUNY Press 1993) 243.

${ }^{39}$ B. Williams, 'Moral Luck: A Postscript', in Making Sense of Humanity and other Philosophical Papers, 1982-1993, (Cambridge University Press, 1995) 241.

${ }^{40}$ T. Nagel, 'Moral Luck', in Mortal Questions (Cambridge University Press, 1979) 36 .

${ }^{41}$ Walker (n 38) 243.
} 
face of responsibility. ${ }^{42}$ In deciding whether one is morally responsible in the first place, I believe that we only need to address the issue of capacity responsibility, since it is our ability to use reason to guide our actions which allows us to even hold people accountable for what they do or fail to do. What Nagel and Walker are in fact arguing is that we should decide on whether a person is morally responsible based on the idea of virtue responsibility. They suggest that we have to take into account how it is that the environment will inevitably affect the actions of certain people, in order to determine moral responsibility. I believe that this should only matter when we wish to decide the extent of moral responsibility a person should be ascribed, and this is only after we have decided that that person can be morally responsible in the first place. ${ }^{43}$ Therefore, moral luck does not pose a threat to the concept of moral responsibility, although it can prove to be a justification for why some people are more responsible than others.

\section{Neuroscientific Challenges to Moral Responsibility in}

\section{CERTAIN INDIVIDUALS}

Now that I have addressed some of the challenges neuroscience poses to the concept of moral responsibility, we can appreciate that causal explanations cannot exist as an excuse for moral responsibility. In this section of the essay, I will focus on how neuroscience as a causal explanation for behaviour, can provide evidence of the presence of a genuine excusing condition for moral responsibility in certain individuals based on Kantian principles. ${ }^{44}$ I will explore the theoretical limits of the extent to which such causal evidence can show a priori whether an individual can be morally responsible for his or her actions before the alleged immoral behaviour is exhibited. This will be done through two possible defences of impaired cognitive ability and impaired volitional ability which are raised by neuroscience. After setting out the theoretical limits, I will proceed to suggest how neuroscience should fit into the

\footnotetext{
42 G. Watson, 'Two Faces of Responsibility' in Agency and Answerability (Oxford, UK, 2004) 260-88.

${ }^{43}$ N. A. Vincent, 'Madness, Badness and Neuroimaging-Based Responsibility Assessments', in Freeman (n 1) 92-93.

${ }^{44}$ Morse (n 1) 537.
} 
existing framework of behavioural evidence in assessing responsibility where a priori assessment of moral responsibility cannot be done.

\section{A Defence of Impaired Cognitive Ability}

A defence against being morally responsible for one's actions based on lack of cognitive ability is not alien to us. ${ }^{45}$ However, what we mean when we say 'cognitive ability' is less clear. Employing a Kantian conception of moral responsibility and freedom allows us to understand that a lack of cognitive ability essentially means the impaired ability to utilise pure practical reason. I believe that there are in fact two separate categories of reasoning which we need to consider. The first category is with regards to beings whose wills are not guided by imperatives. Even hypothetical imperatives do not command them, because action is arbitrary. The automatism case of Ken Parks illustrates this clearly. Parks drove twenty-three kilometres to Ontario, where he stabbed both his parents-in-law. He then drove to the police station and told the police that he thought he had killed someone. ${ }^{46}$ As reported, only then did Parks notice that his hands were badly injured. Parks was acquitted at trial, and the Canadian Supreme Court on appeal held that Parks committed the act in a state of automatism and was not responsible for his actions. ${ }^{47}$ Therefore, where action cannot be governed by imperatives, an individual cannot be held morally responsible, and we can make this assessment before any behaviour is exhibited. This is, of course, subject to normative valuations of how much lack of consciousness is deemed to mean that the individual is subject to automatism, which cannot be determined by neuroscience.

The second category is with regards to beings whose wills are guided by imperatives, but cannot comprehend categorical imperatives. Therefore, these beings are capable of acting with ends in mind, but their diminished capacity to reason results in them not being able to comprehend the universal moral law which is independent of ends. As mentioned earlier, common examples of such beings are mentally

\footnotetext{
${ }^{45}$ Roper v Simmons, 543 US. 551 (2005).

${ }^{46}$ R. Broughton, R. Billings, R. Cartwright et al., 'Homicidal somnambulism: a case report', (1994) Sleep 17: 254-64.

${ }^{47}$ N. Levy and T. Bayne, 'Doing without deliberation: automatism, automaticity, and moral accountability' (2004) International Review of Psychiatry 16: 209-15.
} 
disabled or insane people. Therefore, as long as neuroscientific evidence can show the lack of capacity for pure practical reason, we know a priori that a being cannot be morally responsible for its actions. However, it might not always be the case that neuroscience will provide definitive evidence of a causal connection between imaging data showing brain dysfunction and the incapacity to respond to moral reasons against certain actions. ${ }^{48}$ Such a difficulty might be resolved as brain science develops, and we will not consider this to be an issue at present.

Currently, there are other challenges to why neuroscience might not be able to show this lack of capacity for reason. An example of this would be the case of psychopaths. Neuroscientific studies have shown that psychopaths suffer from amygdala dysfunction. ${ }^{49}$ The amygdala is a central part of the emotional brain and affects our ability to recognise sad and fearful expressions in other people, and also to differentiate between types of wrong-doing. There are two such categories of wrongs conventional transgressions and moral transgressions. ${ }^{50}$ Conventional transgressions are wrongs which are based on the existence of authority or rule. Moral transgressions are based on the wrongful nature of the act in itself. Psychopaths have been shown to be unable to reliably distinguish between moral and conventional transgressions. When psychopaths were asked why something was wrong, the only explanations given were because the rules said so, as opposed to reasons citing the harmful nature of the act on others. ${ }^{51}$ Adopting a Kantian analysis, psychopaths cannot understand the binding nature of the moral law on their actions, because although they know that they are bound by laws, these laws to them are not categorical imperatives, but merely hypothetical. This is an important distinction to make, because one does not doubt the ability of psychopaths to appreciate the action-guiding nature of reason which makes them will an end. In fact, this is often the very reason why many people regard psychopaths 'as bad, not mad'.52

${ }^{48}$ W. Glannon, 'What Neuroscience Can (and Cannot) Tell Us about Criminal Responsibility', in Freeman (n 1) 27.

49 J. Blair, D. Mitchell, and K. Blair, The Psychopath: Emotion and the Brain (Blackwell, 2005).

$50 \mathrm{E}$. Turiel, The development of social knowledge: morality and convention, (Cambridge University Press, 1977).

${ }^{51}$ Levy (n 29) 249.

${ }^{52}$ ibid. 248. 
However, the limits of brain science in excusing psychopaths from responsibility were tested by psychologist Robert Hare. In the Hare Psychopathy Checklist, Hare argues that psychopathy is an aggravating rather than a mitigating factor. ${ }^{53}$ It is not clear whether abnormalities in the brain of psychopaths caused the behaviour, or whether the brain abnormality was a result of behaviour over time. ${ }^{54}$ This is another area which neuroscience will have to address if it is to work as evidence of a lack of capacity to reason.

\section{A Defence of Impaired Volition}

Individuals might also seek to use neuroscientific evidence to disclaim moral responsibility by arguing that they have an impaired ability to control their behaviour. An example of this would be the ability to control violent impulses. Neuroscience has produced findings through imaging of the brain, which show that many impulsive murderers have reduced activity in the prefrontal cortex and increased activity in the amygdala ${ }^{55}$. These images suggest that these murderers had significantly impaired impulse control. A preliminary point to note is that individuals who employ this line of argument do not propose that they are incapable of understanding the moral law which obligates them. Therefore, when committing immoral acts, these people are fully aware that they are not acting from duty to uphold the moral law.

I will argue that when neuroscientific evidence can show the total lack of capacity to inhibit impulse, it can serve as a priori evidence for excusing moral responsibility through establishing a strong causal connection between the relevant brain dysfunction and loss of control. Kantian moral philosophy is premised on the notion that we are both beings in the phenomenal world where we are subjected to the laws of nature, and in the noumenal world where we are autonomous beings subjected to the universal moral law. ${ }^{56}$ An individual who lacks the

\footnotetext{
${ }_{54}^{53}$ R. Hare, The Hare Psychopathy Checklist ( $2^{\text {nd }}$ ed, Multi-Health Systems, 2003).

54 Glannon, "What Neuroscience Can (and Cannot) Tell Us about Criminal Responsibility' (n 48), 22-23.

${ }^{55}$ R. J. Davidson, K. M. Putnam, and C.L. Larson, 'Dysfunction in the Neural Circuitry of Emotion Regulation - A possible Prelude to Violence' (2000) 289 Science 591-594.

${ }^{56}$ Kant, Groundwork for the Metaphysics of Morals (n 4), 57/452.
} 
capacity to inhibit his impulses is one who is governed solely by the laws of nature, because he is unable to affect his actions through his will governed by the moral law. Therefore, we can conclude that such individuals should not be held morally responsible for their actions, as they are merely agents of external causes, rather than legislators of the first causes in the world. ${ }^{57}$ The famous case of an American teacher in Virginia who started displaying paedophilic tendencies due to a meningioma pressing on his orbitofrontal cortex is a clear example of this. The teacher after making advances to his 12 year-old stepdaughter, was removed from his home and ordered to complete a 12-step residential problem for sexual addiction or he would go to prison. Although he was strongly motivated to not go to prison, the teacher solicited sex from clients and staff of the program and was expelled from it. Before his sentencing, the tumour in his brain was discovered and removed, which resolved the paedophilia. However, this paedophilia returned with the growth of a new tumour in the same brain region, only to go away again after a second removal. ${ }^{58}$ This was a case where neuroscientific evidence could show a strong causal connection between the existence of the tumour and the behaviour of the teacher. The teacher would rightly not be morally responsible for any subsequent paedophilic tendencies exhibited, so long as neuroscientific evidence could prove the same causal connection. Therefore, it is theoretically possible that the loss of capacity to inhibit impulse proved by neuroscience can serve as an $a$ priori excusing condition for moral responsibility.

Now that I have established this possibility, I will discuss a case of how neuroscience is a priori unable to provide proof of an excusing condition for moral responsibility. One such case would be people suffering from Tourette Syndrome (TS). TS is characterised by frequent physical tics and at least one vocal tic. ${ }^{59} 10 \%$ of people suffering from TS have a vocal tic called coprolalia, which makes them use crude and

57 C. M. Korsgaard, 'Morality as freedom' in Creating the Kingdom of Ends (Cambridge University Press 2000) 163.

${ }^{58}$ H. T. Greely, 'Neuroscience and Criminal Responsibility: Proving 'Can't Help Himself' as a Narrow Bar to Criminal Liability' in Freeman (n 1) 71-73.

${ }^{59}$ J. F. Leckman, R. A. King, D. J. Cohen, 'Tics and tic disorders' in J. F. Leckman and D. J. Cohen, eds., Tourette's Syndrome - Tics, Obsessions, Compulsions. (John Wiley and Sons, Inc. 1999) 23-41. 
obscene language for no reason. We get a clear sense of the extent to which TS sufferers attempt to control their impulses from various studies. One study showed that a TS sufferer would bang his head against surfaces, push his fingers up his nose till blood gushed out and hit his own face, to the extent that he sometimes broke his nose. ${ }^{60}$ Other reports show that sufferers of TS would resign from their jobs, and relocate their lives in order to remove themselves from situations which cause them to feel the impulse to act in a way which they know is harmful to themselves and to others. ${ }^{61}$ However, neuroscientific evidence can only show that TS sufferers have some capacity to inhibit impulses but find it difficult to do so. Since Kant recognises that human beings are contingently rational, we know that imperatives command our will in the form of a law. TS is an example of the extent of the practical limits to which reason can govern our actions. However, as long as there is a capacity to inhibit one's impulses, no matter how difficult it may be, one can be morally responsible when reason succumbs to inclination. Also, just because neuroscientific evidence shows a diminished capacity to inhibit impulse does not give anyone a blanket excusing factor for all kinds of wrongdoing. To draw an analogy from cases of coercion and acting under duress, we still find people morally responsible for their actions, even though the extent of responsibility is mitigated (sometimes to the point of non-existence) depending on the circumstances. ${ }^{62}$ In such instances where neuroscience cannot show a total loss of capacity to inhibit impulse, behavioural evidence will be needed as well, in order to provide an excusing or mitigating condition for moral responsibility.

\section{How Neuroscientific Evidence can Help Inform Us of Moral Responsibility regarding Certain Individuals}

In cases where neuroscience can establish the lack of consciousness when acting, incapability to utilise pure practical reason, or when there is a total loss of impulse inhibition, we can conclude that individuals suffering from these problems cannot be morally responsible for their actions $a$ priori of any behavioural evidence. However, when neuroscience can

\footnotetext{
60 ibid.

61 ibid.

${ }^{62}$ Levy (n 29) 252.
} 
only show these various conditions to a certain degree, I will argue that neuroscience can help to establish the presence of an excusing or mitigating condition for immoral action, but only when supported by behavioural evidence.

As mentioned earlier, the automatism defence is subject to the normative judgment of how much consciousness a person must have to be deemed as a subject of automatism. However, once this line is established, it is theoretically impossible to set out a sliding scale of automatism. Either a being is capable of being governed by imperatives, or his actions are arbitrary. There is no in between. Behavioural evidence is not a factor in this defence, since we only seek to establish that a person was a subject of automatism, and whatever actions committed as a result is inconsequential.

For cases of incapacity to reason, assuming that there is evidence showing that brain dysfunction caused the lack of capacity to reason, I believe that moral responsibility can be mitigated. Since we are contingently rational beings who are bound by both laws of nature and the moral law, our capacity for reason comes in degrees along a spectrum. ${ }^{63}$ If an individual is impaired in his capacity to reason, he or she will be less able to affect his actions in the world through obeying the moral law. Therefore, the primary means of assessing a person's culpability will have to be done from evidence of the behaviour of that person. An example of this is would be adolescent criminals, who are deemed to have a lesser capacity for reason than adults. ${ }^{64}$ Presumably, this lower capacity for reason does not meet the criteria established to show total inability for pure practical reason. However, in order for the extent of mitigation to be decided upon, we have to first identify the behaviour of the adolescent, and match the seriousness of his or her immoral acts with the lack of capacity for reason. An example would be an adolescent who committed murder. The first thing we should do is to assess his actions, and make a judgment as to whether a lower capacity for reason would necessarily mean that the adolescent did not know the gravity of his actions. The neuroscientific evidence will only serve to

\footnotetext{
${ }^{63}$ W. Glannon, Bioethics and the Brain (Oxford University Press 2007) 57.

${ }^{64}$ Roper $v$ Simmons, 543 US. 551 (2005).
} 
reinforce our judgment, if we so decide that the adolescent was of an age which meant that he did not comprehend how immoral his act was. ${ }^{65}$

Regarding volitional defences, evidence showing anything less than a total loss of control to inhibit impulses cannot act as an excusing condition. The degree of moral responsibility to be ascribed, however, is another matter altogether. Using the example of TS sufferers, we can see that some of the sufferers go to great lengths to control their impulses. Such behavioural evidence will allow us an insight into the circumstances of how diminished control over a particular impulse afflicts TS sufferers. Neuroscientific evidence showing that TS sufferers have some capacity to inhibit impulses but find it difficult to do so coupled with behavioural evidence can form a basis for mitigating the moral responsibility of people suffering from TS.

\section{E. Neuroscience ANd Legal DoCtRines}

As far as our understanding of moral responsibility allows us to ascribe a degree of culpability on individuals, it cannot serve as the only basis for justice. ${ }^{66}$ Kant made this point in his jurisprudential writings, when he separated the offices of law and morality. ${ }^{67}$ However, our legal system is undoubtedly informed by Kantian moral philosophy and moral responsibility. One such aspect is the law's concept of a person. A legal person is one who is capable of acting intentionally and for reasons. The law treats all people as practical reasoners, and simply assumes that all human beings unless proven otherwise are capable of acting for reasons and have rationality according to mostly conventional, socially constructed standards. ${ }^{68}$ Therefore, the idea of legal responsibility is only possible if we treat human beings as capable of using reasons derived from moral and legal rules as potential guides to acting. ${ }^{69}$ This is what Stephen Morse calls the 'folk psychological' view of the person and

\footnotetext{
${ }^{65}$ N. A. Vincent, 'Responsibility: distinguishing virtue from capacity' (2009) 3 Polish Journal of Philosophy 115.

${ }^{66}$ S. K. Houser, 'Metaethics and the Overlapping Consensus' (1993) 54 Ohio St. L. J. 1139.

${ }^{67}$ Blumoff (n 34) 185.

${ }^{68}$ S. Morse, 'New Neuroscience, Old Problems: Legal Implications of Brain Science' in Glannon (n 3) 197.

${ }^{69}$ ibid.
} 
behaviour. $^{70}$ That said, most legal systems do not just serve the purpose of retribution for moral wrongdoing. The law also seeks to guide action, by informing people of what is undesirable conduct so that they can plan their lives. The law also serves the purpose for specific deterrence of future bad actions by any one defendant and general deterrence of bad actions by others in the population. In the area of criminal law, ascribing legal responsibility strives to prevent future crimes by incapacitating convicted criminals, and even rehabilitation. ${ }^{71}$ With these thoughts in mind, I will discuss three potential contributions neuroscience can make to the doctrine of legal responsibility.

\section{Altering or Abandoning Certain Folk Psychologies}

Neuroscience can help demonstrate that certain folk psychological criteria underlying a particular legal doctrine is wrong, and thus suggest how that doctrine should be changed or abandoned. However, neuroscientific evidence proving this must show specifically how the data obtained confirms or challenges the underlying folk psychological assumptions. It is not enough to just show whether the brain plays a causal role in action, since as stated earlier, causation is never an excuse for responsibility on its own. For example, neuroscience may also teach us about cognitive processing under stress which could conceivably influence our doctrines on informed consent. ${ }^{72}$ Also, neuroscience might help to show that 'excited utterances' as an exception to the hearsay rule in criminal evidence might be misguided, if brain imaging can demonstrate that excitement might decrease accuracy of recalling past memories. ${ }^{73}$ However, one has to keep in mind that any such scientific data which seeks to reform our evidential practices will have to be backed by valid data which are genuinely relevant to the particular doctrine, and also show that changes made to established practices will be beneficial. ${ }^{74}$

\footnotetext{
${ }^{70}$ Morse (n 1) 529.

${ }^{71}$ Greely (n 58) 61.

${ }^{72}$ Morse "New Neuroscience, Old Problems: Legal Implications of Brain Science" (n 68) 203.

${ }^{73}$ Morse (n 1) 541.

${ }^{74}$ Morse (n 68) 202.
} 


\section{Possibilities of New Legal Doctrines}

Secondly, neuroscience can help us to bring about change in legal doctrine or practices. In cases where it is found that there is a lack of consciousness when acting, incapability to utilise pure practical reason, or when there is a total loss of impulse inhibition through neuroscientific evidence, it would be pointless to apply certain legal doctrines. An example of this would be in the case of automatism. Since a person suffering from automatism does not have any idea of what he or she is doing, it would be pointless for the prosecution to attempt to establish the mens rea of the crime. This is not to say that such individuals should not be prosecuted, since the criminal law also serves purposes of rehabilitation and protection of society against certain harmful individuals. It would just mean that it might be appropriate for the law to establish new criteria for conviction when individuals of the above mentioned situations are involved. Also, neuroscientific evidence can help to confirm that some categories of defendants have a much greater difficulty obeying the law in cases of provocation and temptation. In the interest of justice, it might therefore be justifiable for the criminal law to adopt a generic partial mitigating doctrine, rather than to leave it to the discretion of the judge during sentencing. ${ }^{75}$

\section{Implementation of Sentencing Policies}

Our current law of criminal sentencing, and civil judgments with elements of specific performance or commitment, are based on predictions of future behaviour of the parties. Neuroscience can help to reinforce or improve the criteria for such judgments. This is probably the most straightforward case for application, since rather than focusing on analysing the specific mental states of individuals, it is the neuroscientific studies of certain groups of people which will be utilised. ${ }^{76}$ Neuroscience can improve predictions of how certain groups of individuals will benefit from treatment programs or suspended sentences. It can also provide valuable information as to the prophylactic or rehabilitative use of various sentencing measures for people with neurological problems, such as

\footnotetext{
${ }^{75}$ S. Morse (n 1) 541- 542.

76 ibid, 542.
} 
children with low-MAOA activity who also suffered early childhood abuse. $^{77}$

Although academics such as Searle have warned us that we need to incorporate scientific research into current normative frameworks for legal responsibility in order to prevent our legal model from being outmoded, ${ }^{78}$ we have to be cautious in falling prey to what Morse calls 'brain overclaim syndrome'. ${ }^{79}$ The ruling by the United States Supreme Court in Roper $v$ Simmons ${ }^{80}$ underscores this very point, where the court was astute in not being overwhelmed by the imaging studies of adolescent brains presented to them by the amicus curiae brief. Instead, the majority opinion was based on developmental psychology and common sense observation that adolescents are on average less rational than adults. ${ }^{81}$ Such an approach would allow for the law to develop in an organic and sensible manner, by taking into account developments in science while not being overzealous in concluding that our current legal presumptions are erroneous.

\section{F. CONCLUSion}

This essay has discussed how neuroscience should affect our concept of moral responsibility derived from Kantian moral philosophy. In the absence of any resolution of the metaphysical problem of free will, neuroscience does not pose a threat to the existence of moral responsibility. However, with respect to certain cases, neuroscience can inform us that certain individuals cannot be morally responsible for their actions. Also, certain legal doctrines and practices can benefit from the advancements in neuroscience, and should be encouraged. To put things in perspective, the current extent of neuroscientific development does have its limitations. We have to recognise that a person's behaviour is influenced by a multitude of factors, such as genetic, endocrinological, social and economic among others, and that it will be difficult in most

\footnotetext{
77 ibid, 535.

${ }^{78}$ J. Searle, Mind, (Oxford University Press 2004) 209.

${ }^{79}$ S. Morse 'Brain Overclaim Syndrome and Criminal Responsibility: A Diagnostic Note' (2006) 3 Ohio State Journal of Criminal Law 397.

${ }^{80}$ Roper $v$ Simmons, 543 US. 551 (2005).

81 Glannon, 'What Neuroscience Can (and Cannot) Tell Us about Criminal Responsibility' (n 48) 28.
} 
instances to say that a brain image will be able to show culpability or nonculpability. ${ }^{82}$ As long as we adopt neuroscience within our current normative frameworks of free will and responsibility, the rapid advancement in our understanding of the mechanistic functions of our brain and its relationship with the mind, will allow us to work out exactly when we can hold someone responsible for his or her actions.

${ }^{82}$ D. Mobbs, H. C. Lau, O. D. Jones, and C. D. Frith, 'Law, Responsibility and the Brain', in M. Freeman and O. R. Goodenough (n 78), 20. See also, M. Gazzaniga, The Ethical Brain (Dana Press, 2005) 100. 